\title{
Perfil químico e atividades antioxidante e antifúngica dos óleos essenciais de Raulinoreitzia crenulata (Spreng.) R. M. King \& H. Rob.
}

\author{
Antonio Carlos Pereira de Menezes Filho, ${ }^{1,3}$ Luzia Francisca de Souza2; Carlos Frederico de \\ Souza Castro ${ }^{1}$ \\ ${ }^{1}$ Instituto Federal de Educação, Ciência e Tecnologia Goiano, Campus Rio Verde; ${ }^{2}$ Universidade Federal de \\ Jataí; ${ }^{3}$ astronomoamadorgoias@gmail.com
}

Pereira de Menezes Filho Antonio Carlos; Luzia Francisca de Souza; Carlos Frederico de Souza Castro (2020). Perfil químico e atividades antioxidante e antifúngica dos óleos essenciais de Raulinoreitzia crenulata (Spreng.) R. M. King \& H. Rob. Rev. Fac. Agron. Vol 119 (2): 1-12. https://doi.org/10.24215/16699513e052

Raulinoreitzia crenulata é uma espécie vegetal pertencente à família Asteraceae, apresentando compostos aromáticos nos galhos, folhas e flores. O objetivo deste trabalho foi avaliar o perfil químico e as atividades antioxidante pela redução do DPPH e antifúngica frente à Sclerotinia sclerotiorum, Colletotrichum gloeosporioides e Colletotrichum acutatum pelos óleos essenciais dos galhos, folhas e flores de $R$. crenulata. O material biológico foi coletado em uma área no município de Rio Verde, Goiás, Brasil. O óleo essencial foi extraído e o rendimento determinado. O perfil químico dos óleos essenciais foi determinado por CG-EM, a atividade antioxidante pela redução do radical livre DPPH e a atividade antifúngica por sucessivas diluições do óleo essencial em Dimetilsulfóxido. Os rendimentos dos óleos essenciais foram de 0,$82 ; 0,64$ e $0,09 \%$ para galhos, folhas e flores respectivamente. O perfil químico apresentou 33 compostos para o óleo dos galhos, 29 para o óleo das folhas e 28 compostos para o óleo das flores. A atividade antioxidante apresentou redução entre 100 a 25,09\% para o óleo dos galhos, de 86,09 a $17,21 \%$ para o óleo das folhas e de 20,55 a $15,12 \%$ para o óleo das flores. A inibição de crescimento micelial para $S$. sclerotiorum apresentou os melhores resultados, seguido de $C$. gloeosporioides e em menor atividade fungistática para $C$. acutatum. Os resultados obtidos neste estudo apresentaram bons rendimentos de extração de óleo, eficientes atividades antioxidante e antifúngica. Os óleos essenciais de Raulinoreitzia crenulata apresentaram bons indicadores através dos ensaios laboratoriais para uso agrícola, biológico, farmacêutico e alimentício.

Palavras-chave: atividade antioxidante; Raulinoreitzia; Sclerotinia sclerotiorum; Colletotrichum gloeosporioides

Pereira de Menezes Filho Antonio Carlos; Luzia Francisca de Souza; Wendel Cruvinel de Sousa; Carlos Frederico de Souza Castro (2020). Chemical profile and antioxidant and antifungal activities of essential oils of Raulinoreitzia crenulata (Spreng.) R. M. King \& H. Rob. Rev. Fac. Agron. Vol 119 (2): 1-12. https://doi.org/10.24215/16699513e052

\begin{abstract}
Raulinoreitzia crenulata is a plant species in the Asteraceae family, presenting aromatic compounds in twigs, leaves and flowers. The objective of this work was to evaluate the chemical profile, radical scavening activity reducing of DPPH and antifungal properties against Sclerotinia sclerotiorum, Colletotrichum gloeosporioides and Colletotrichum acutatum of the essential oils of $R$. crenulata twigs, leaves and flowers. The biological material was collected from an area in Rio Verde, Goiás, Brazil. The essential oil was extracted and the yield determined. The chemical profile of the essential oils was determined by GC-MS, the antioxidant activity by the DPPH free radical reduction and the antifungal activity by successive dilutions of the essential oil in Dimethylsulfoxide. The yield of the essential oils was $0.82 ; 0.64$ and $0.09 \%$ for twigs, leaves and flowers respectively. The chemical profile showed 33 compounds for twigs oil, 29 for leaf oil and 28 compounds for flower oil. Antioxidant activity decreased from 100 to $25.09 \%$ for twing oil, from 86.09 to $17.21 \%$ for leaf oil and from 20.55 to $15.12 \%$ for flower oil. The inhibition of mycelial growth for $S$. sclerotiorum showed the best results, followed by $C$. gloeosporioides and with lower fungistatic activity for $C$. acutatum. The results obtained in this study showed good oil extraction yields, efficient antioxidant and antifungal activities. Raulinoreitzia crenulata essential oils showed good indicators through laboratory tests for agricultural, biological, pharmaceutical and food use.
\end{abstract}

Key words: antioxidant activity; Raulinoreitzia; Sclerotinia sclerotiorum; Colletotrichum gloeosporioides

https://revistas.unlp.edu.ar/revagro

Recibido: $11 / 11 / 2019$

Aceptado: $15 / 04 / 2020$

Disponible on line: $07 / 12 / 2020$

ISSN 0041-8676 - ISSN (on line) 1669-9513, Facultad de Ciencias Agrarias y Forestales, UNLP, Argentina 


\section{INTRODUÇÃO}

A família Asteraceae compreende entre 1600 a 1700 gêneros e aproximadamente 24000 espécies distribuídas em três subfamílias e 17 tribos, apresentando distribuição mundial entre 8 a $12 \%$ do total de angiospermas (Hattori \& Nakajima, 2011; Heiden et al., 2007; Bremer, 1994). No Brasil a familia Asteraceae apresenta grande importância observada em inúmeros trabalhos de campo no levantamento florístico, visto que, esta família apresenta entorno de $10 \%$ do total observado. Esta grande parcela, está relacionada à dispersão por frutos e sementes das inúmeras espécies vegetais que compõem esta família (Heiden et al., 2007).

A espécie Raulinoreitzia crenulata (Spreng.) R.M. King \& H. Rob., é encontrada no Brasil, Peru, Bolívia, Paraguai e no Nordeste da Argentina, com morfologia arbustiva ca. 1,5-3 $\mathrm{m}$ de altura; com ramos angulosos, estriados, glabros; as folhas são simples, opostas, e o pecíolo apresenta até $12 \mathrm{~mm}$, a lâmina foliar é do tipo elíptico a obovada; o ápice é obtuso a arredondado ou agudo a acuminado; a margem foliar é serreada ou crenada, com base aguda ou acuminada; ambas as faces glandulosa; apresentam flores pentâmeras, perfeitas, alvas, com corola tubulosa, tubo glanduloso, com ápice 5-lobado, lobo glandulosos de coloração branca e leve aroma adocicado, sua floração compreende entre os meses de janeiro a maio (Hattori \& Nakajima, 2011; Souza et al., 2007). Esta espécie era anteriormente conhecida por Eupatorium polystachyum, hoje o gênero Eupatorium sofreu segregação e esta espécie foi classificada e chamada de $R$. crenulata.

No Brasil a $R$. crenulata foi observada em estudos desenvolvidos nos estados do Piauí, Minas Gerais, Mato Grosso do Sul, Goiás, São Paulo, Paraná, Santa Catarina, Rio Grande do Sul e no Distrito Federal. Esta espécie é encontrada habitando áreas de campo sujo úmido, de transição Cerrado sentido restrito-vereda e vereda. A espécie de $R$. crenulata é facilmente confundida com $R$. tremula, pelos capítulos dispostos em espigas formando panículas, mas difere desta pelo formato do limbo foliar sendo mais ovada a elíptica em $R$. crenulata e mais linear em $R$. tremula (Hattori \& Nakajima, 2011).

Várias espécies de Asteraceae apresentam compostos de óleo essencial produzidos naturalmente pelos vegetais como uma das inúmeras classes de compostos do metabolismo secundário. Os óleos essenciais são constituídos basicamente por monoterpenos, diterpenos, sesquiterpenos e fenilpropanóides (Ribeiro et al., 2018). Estas classes químicas em sinergismo ou individuais apresentam importantes funções biológicas, farmacêuticas, agrícolas e alimentícias. Na agricultura os óleos essenciais vêm apresentando em estudos in vitro boa eficiência no controle de fitopatógenos, como inseticidas, moluscicidas, larvicidas, antifúngicos e acaricidas (Gomes et al., 2019; Valente et al., 2018; Volpato et al., 2018; Estrela et al., 2006). Entretanto, estes compostos naturais voláteis apresentam também para as indústrias de alimentos e farmacêuticas importantes ações como na atividade antioxidante, bactericida, antitumoral e antiviral (Maleski et al., 2019; Tariq et al., 2019; Souza et al., 2012; Allahverdiyev et. al., 2004).
Os principais compostos majoritários encontrados nos óleos essenciais de Asteraceae são $\alpha$-pineno, $\beta$-pineno, D-limoneno, sabineno, $\alpha$-felandreno, germacreno $D, \beta$ cariofileno e biciclogermacreno como terpenos hidrocarbonados (Sobrinho et al., 2017; Maia et al., 2010; Maia et al., 2002). Na classe de compostos terpênicos oxigenados são descritos o espatulenol e globulol (Maia et al., 2002).

Estudo desenvolvido por Souza et al. (2007) avaliaram os compostos químicos de óleos essenciais de $E$. polystachyum ( $=R$. crenulata) a partir dos órgãos foliar e das inflorescências, onde obtiveram como compostos majoritários o $\beta$-pineno, $\beta$-mirceno, $D$-limoneno, $\beta$ cariofileno, germacreno $D$ e biciclogermacreno. Os pesquisadores ainda avaliam a atividade antioxidante pelo radical DPPH como modelo, onde em ambas as amostras de óleos voláteis apresentaram completa neutralização do radical livre. Outras espécies do gênero Eupatorium como E. macrophyllum, E. laevigatum, E. squalidum, $E$. amygdalinum, $E$. conysoides e $E$. marginatum avaliados na região da Amazônia brasileira apresentaram os compostos sabineno, limoneno, $\alpha$ gurjuneno, $\beta$-cariofileno, germacreno $D$, spatulenol, óxido de cariofileno, globulol, aristoloqueno + leavigatin como compostos majoritários dentre as espécies (Maia et al., 2002).

Os óleos essenciais apresentam importante função agrícola, como eficiente agente fungicida natural no controle ou mesmo na eliminação de pragas. Novos produtos naturais com características antifúngicas e fungistáticas vêm sendo desenvolvidas na promoção, bem como substituição gradativa dos agentes antifúngicos sintéticos, que agridem o ambiente a cada ciclo de plantio. Inúmeras espécies fúngicas vêm se adaptando as doses aplicadas nas lavouras, levando o aparecimento de espécies resistentes, isso promove a produção ou mesmo o aumento das doses lançadas durante a cultura (Carmona \& Sautua, 2017).

Em especial o mofo-branco (Sclerotinia sclerotiorum), e as diversas formas de antracnose, sendo 0 Colletotrichum gloeosporioides e Colletotrichum acutatum exemplos de agentes fitopatogênicos que todos os anos causam exponencial perdas na agricultura e no armazenamento de grãos (soja, milho, sorgo, grão-debico), bem como durante o transporte de frutas como morango, manga, mamão, abacate e banana (Martinazzo et al., 2019; Silva et al., 2018; Bagherabadi et al., 2018; Freddo et al., 2016; Amaike \& Keller, 2011 ).

O trabalho teve por objetivo avaliar os óleos essenciais dos galhos, folhas e flores de Raulinoreitzia crenulata, quanto ao perfil químico e suas atividades antioxidantes na redução do radical livre DPPH e antifúngica frente à Sclerotinia sclerotiorum, Colletotrichum gloeosporioides e Colletotrichum acutatum em diferentes concentrações.

\section{METODOLOGIA}

Foram coletados galhos, folhas e flores de $R$. crenulata em uma área de brejo localizado em uma propriedade rural no município de Rio Verde - GO, Brasil, com a seguinte localização geográfica: 1743'05.7'S $50^{\circ} 53^{\prime} 09.6^{\prime \prime} \mathrm{W}$. A espécie foi identificada pela Prof ${ }^{\mathrm{a}}$. Dr ${ }^{\mathrm{a}}$. Luzia Francisca de Souza do Herbário Jataiense, Universidade Federal de Jataí - GO, Brasil. Uma exsicata 
foi herborizada e depositada no Herbário do Instituto Federal Goiano, campus Rio Verde - GO, Brasil, com o seguinte número HRV: 1114.

As amostras foram coletadas em março de 2019 entre as 6-8 h. O material foi levado para o laboratório de Química Tecnológica onde foi limpo em água corrente e separado por órgão vegetativo. O material depois de seccionado, foi pesado em alíquotas de $100 \mathrm{~g}$ e triturado separadamente em processador doméstico com $500 \mathrm{~mL}$ de água destilada. Em seguida, a solução foi transferida para sistema tipo Clevenger onde ficou em refluxo por 4,5 h. Logo após, o hidrolato foi transferido para funil de separação, onde foi lavado 3 vezes com $30 \mathrm{~mL}$ de diclorometano (P.A - ACS). A fração orgânica foi coletada e seca com sulfato e sódio anidro (P.A - ACS). O sobrenadante foi então transferido para um copo tipo béquer revestido externamente com papel alumínio, e deixado em local seco, fresco e ao abrigo da luz até completa evaporação do solvente. Em seguida, o óleo essencial foi pesado, e o rendimento expresso em porcentagem conforme descrito por Menezes Filho et al. (2020).

A análise da constituição química do óleo essencial dos galhos, folhas e flores de $R$. crenulata, foi realizada em Sistema de Cromatógrafo a gás acoplado a Espectrômetro de Massas Sequencial (CG - EM), equipado com auto-injetor (Shimadzu), coluna Restek Rtx-5ms (30m x $0.250 \mathrm{~mm} \times 0.25 \mu \mathrm{m})$ fundida com sílica e Espectrômetro de Massas Sequencial (Shimadzu) e detector por ionização por impacto eletrônico (IE) $(70$ eV). A temperatura inicial foi mantida a $60{ }^{\circ} \mathrm{C}$ por $3,0 \mathrm{~min}$., seguido de um acréscimo de $3{ }^{\circ} \mathrm{C}$ min $^{-1}$ até atingir $200{ }^{\circ} \mathrm{C}$ e posteriormente foi programada para um aumento de temperatura de $15^{\circ} \mathrm{C}$ min $^{-1}$ até $270{ }^{\circ} \mathrm{C}$, permanecendo nessa temperatura por mais $1,0 \mathrm{~min}$.

As temperaturas do injetor e do detector foram de $250^{\circ} \mathrm{C}$ e $300^{\circ} \mathrm{C}$. As analises foram realizadas utilizando gás $(\mathrm{He})$ como carreador com pressão de injeção de $50 \mathrm{KPa}$, faixa de detecção do espectrômetro de massas: 43-600 m/z: 2,0 min e fluxo de $3 \mathrm{~mL} \mathrm{~min}^{-1}$. A identificação dos componentes dos óleos essenciais foi baseada pelo índice de retenção linear (Índice de Kovats) (IK) calculado em relação aos tempos de retenção da série homóloga de n-alcanos (C-06 a C-42) e no padrão de fragmentação observado nos espectros de massas, por comparação destes com a literatura (Adams, 2007) e da espectroteca (Nist 11).

A atividade antioxidante foi determinada conforme Mezza et al. (2018) adaptado. Utilizou-se o radical livre DPPH (2,2-difenil-1-picrilhidrazil). O ensaio antioxidante foi realizado pelo método de microdiluição em microplacas de 96 poços, utilizando leitora de microplacas (Polaris, Mod. EE). Para cada poço foram adicionados $100 \mu \mathrm{L} \mathrm{mL}^{-}$ 1 de uma solução diclorometânica de DPPH na concentração $0,06 \mathrm{mM}, 100 \mu \mathrm{L} \mathrm{mL} \mathrm{m}^{-1}$ de óleo essencial diluído em diclorometano nas seguintes diluições com concentrações de $50 ; 40 ; 30 ; 20 ; 10 ; 5 ; 2,5 ; 1,25$ e 0,625 $\mu \mathrm{L} \mathrm{mL} \mathrm{m}^{-1}$. A microplaca com as amostras foi mantida sob refrigeração a $-8{ }^{\circ} \mathrm{C}$. As leituras foram realizadas no comprimento de ondas em 517 nm, após $1 \mathrm{~h}$. de reação. Uma curva padrão foi realizada com a solução de DPPH na concentração $0,06 \mathrm{mM}$. Como controle negativo utilizou-se a solução mãe de DPPH 0,06 mM, e como branco o diclorometano. Os resultados foram expressos em percentagem de redução de DPPH (\%).
Os fungos mantidos em meio batata-dextrose-ágar (BDA) foram obtidos por doação pelos laboratórios de Produtos Naturais e de Química Tecnológica. As cepas avaliadas pertencem à coleção micológica do Laboratório de Microbiologia Agrícola do Instituto Federal Goiano, campus do município de Rio Verde - Estado de Goiás, Ministério da Educação do Brasil, sendo a cepa identificada geneticamente por S. sclerotiorum VIW 1243, C. gloeosporioides STW 2115 e C. acutatum STW 2015. As cepas de $S$. sclerotiorum foram coletadas em campos de cultivo de soja na região do município de Rio Verde GO, Brasil. As cepas de C. gloeosporioides e C. acutatum foram coletadas em culturas de mamoeiros e maracujazeiros nos municípios de Itumbiara e Morrinhos - Goiás, Brasil, respectivamente.

A atividade antifúngica foi determinada através da diluição seriada dos óleos essenciais em dimetilsulfóxido (DMSO). As concentrações partiram de 100 (óleo puro); 50; $25 ; 12,5 ; 6,25 ; 3,13$ e 1,56 $\mu \mathrm{L} \mathrm{mL}^{-1}$. Como controle negativo, utilizou-se a testemunha (ausência de óleo) e DMSO, enquanto o controle positivo foi o fungicida Frowncide $^{\circledR} 500 \mathrm{SC}$ na concentração de $10 \mu \mathrm{L} \mathrm{mL}^{-1}$ com as seguintes características (Nome técnico Fluaziman, Registro no Ministério da Agricultura do Brasil: 7695, Empresa registrante ISK, dosagem do ingrediente ativo $500 \mathrm{~g} \mathrm{~L}^{-1}$ (rótulo do produto), e aplicação pelo sistema terrestre ou aéreo por pulverização direta), e DMSO conforme descrito por Menezes Filho et al. (2020).

As concentrações do óleo essencial foram adicionadas ao meio de cultura BDA após esterilização e resfriamento, bem como para os tratamentos com fungicida comercial e DMSO. Após solidificação do meio, em câmara de fluxo laminar, 1 disco de micélio para cada cepa de $S$. sclerotiorum, $C$. gloeosporioides e $C$. acutatum com $9 \mathrm{~mm}$ de diâmetro, foi depositado no centro da placa de Petri de $9 \mathrm{~cm}$ de diâmetro. Em seguida, foram incubadas à temperatura de 20, 23 e 25 ${ }^{\circ} \mathrm{C}$, com fotoperíodo de 12 horas, para S. sclerotiorum, $C$. acutatum e C. gloeosporioides respectivamente, conforme descrito por Silva et al. (2018), Cunico et al. (2002) e Celoto et al. (2008) adaptado.

A avaliação consistiu em medições diárias do diâmetro das colônias, por meio de um paquímetro digital (Digimess) com resolução de 0,01 mm/.0005", iniciadas após 24 horas do início da incubação e encerradas, quando as colônias fúngicas, do tratamento testemunha, atingiram completamente a área interna da placa. A determinação do percentual de inibição de crescimento (PIC\%) foi realizada conforme proposto por Garcia et al. (2012). A equação utilizada foi \% PIC = (DTT - DTQ $) /$ DTT $x$ 100. Onde: $P I C=$ percentual de inibição de crescimento, DTT = diâmetro no tratamento testemunha, $\mathrm{DTQ}=$ diâmetro no tratamento químico.

A análise estatística consistiu através de triplicatas para determinação do rendimento e da atividade antioxidante, e de quadruplicata para o teste fúngico, seguido de $( \pm)$ desvio padrão das médias. Os dados foram submetidos à análise de variância (ANOVA) e as médias de todos os tratamentos com óleo essencial, foram comparadas ao fungicida comercial pelo teste de Scott-Knott, com nível de significância de $5 \%$. Já as médias entre as concentrações para cada óleo essencial, foram avaliadas pelos testes de Tukey, e entre os resultados com apenas duas variações em ambas as concentrações por Student 
$(p \leq 0,05)$. O Software estatístico utilizado foi o PAST 3 (versão livre 2019).

\section{RESULTADOS}

$\mathrm{Na}$ Figura 1 estão apresentados indivíduos de $R$. crenulata com inflorescências em ambiente natural de solo semi-alagado em área de Cerrado goiano, Brasil.

O rendimento do óleo essencial para os galhos, folhas e flores foram de 0,82; 0,64 e de 0,09\% respectivamente.

$\mathrm{Na}$ Tabela 1 está apresentado o perfil químico do óleo essencial dos galhos, folhas e flores de $R$. crenulata por CG-EM.

O perfil químico demonstrou para o óleo essencial dos galhos um total de 33 compostos, sendo os majoritários o-cimeno, germacreno $D, \alpha$-cubebeno e $\beta$-ilangeno. Para o óleo essencial das folhas foram identificados 29 compostos, sendo os majoritários a-cubebeno e $\mathrm{Y}$ elemeno. Já para o óleo essencial das flores foram identificados 28 compostos sendo os majoritários $\delta$-3careno, D-limoneno, germacreno D e humuleno-1,6-dien3-ol. Neste estudo foi observado o composto orcinil ditiglato nos óleos dos galhos e folhas (Tabela 1).

$\mathrm{Na}$ Tabela 2 está apresentado o resultado da atividade antioxidante pelo óleo essencial doa galhos, folhas e flores, na redução do radical livre de DPPH em diferentes concentrações usuais. A atividade antioxidante na redução do radical livre DPPH apresentou maior efetividade para o óleo essencial dos galhos (Tabela 2), com máxima redução do DPPH nas maiores concentrações, e baixa porcentagem de redução na menor concentração usual. O óleo essencial das folhas apresentou média eficiência, onde na maior concentração foi obtida a maiorpercentagem de redução (Tabela 2).
Já para o óleo essencial das flores foi o que demonstrou menor taxa de redução do DPPH entre os demais óleos avaliados de $R$. crenulata. Sendo apenas observada redução discreta e ligeiramente baixa nas maiores concentrações com percentagens de baixa significância, em comparação com as demais amostras (Tabela 2).

As três amostras de óleo essencial, quando comparadas entre si, apresentaram diferença significativa pelo teste de Tukey e Student, nas respectivas concentrações. Não foi observado ação de redução do radical livre em concentrações inferiores a $10 ; 20$ e $40 \mu \mathrm{L} \mathrm{mL}-1$ para os óleos essenciais dos galhos, folhas e flores respectivamente, para $R$. crenulata.

$\mathrm{Na}$ Figura 2 estão apresentados os resultados de porcentagem de inibição de crescimento (PIC) para os óleos dos galhos, folhas e flores de $R$. crenulata frente à $S$. sclerotiorum in vitro na concentrações nas concentrações $(100 ; 50 ; 25 ; 12,5 ; 6,25 ; 3,13$ e $1,56 \mu \mathrm{L}$ $\left.\mathrm{mL}^{-1}\right)$.

Conforme a Figura 2, observam-se alta eficiencia de inibição em porcentagem de crescimento para o fungo $S$. sclerotiorum obtidas pelos óleos essenciais dos galhos, folhas e flores de $R$. crenulata em diferentes concentrações. Pelo teste de Tukey foi observada diferença estatística para a maioria das concentrações para cada óleo essencial. As maiores taxas de inibições foram observadas sempre nas maiores concentrações o óleo das folhas, seguidas das flores e galhos.

Entretanto, o óleo essencial dos galhos demonstrou atividade de inibição em baixa concentração, onde o mesmo não foi observado para os óleos das folhas e flores.

Os óleos apresentaram boa ação fungistática sensibilizando o desenvolvimento das hifas do $S$. sclerotiorum (Figura 2).

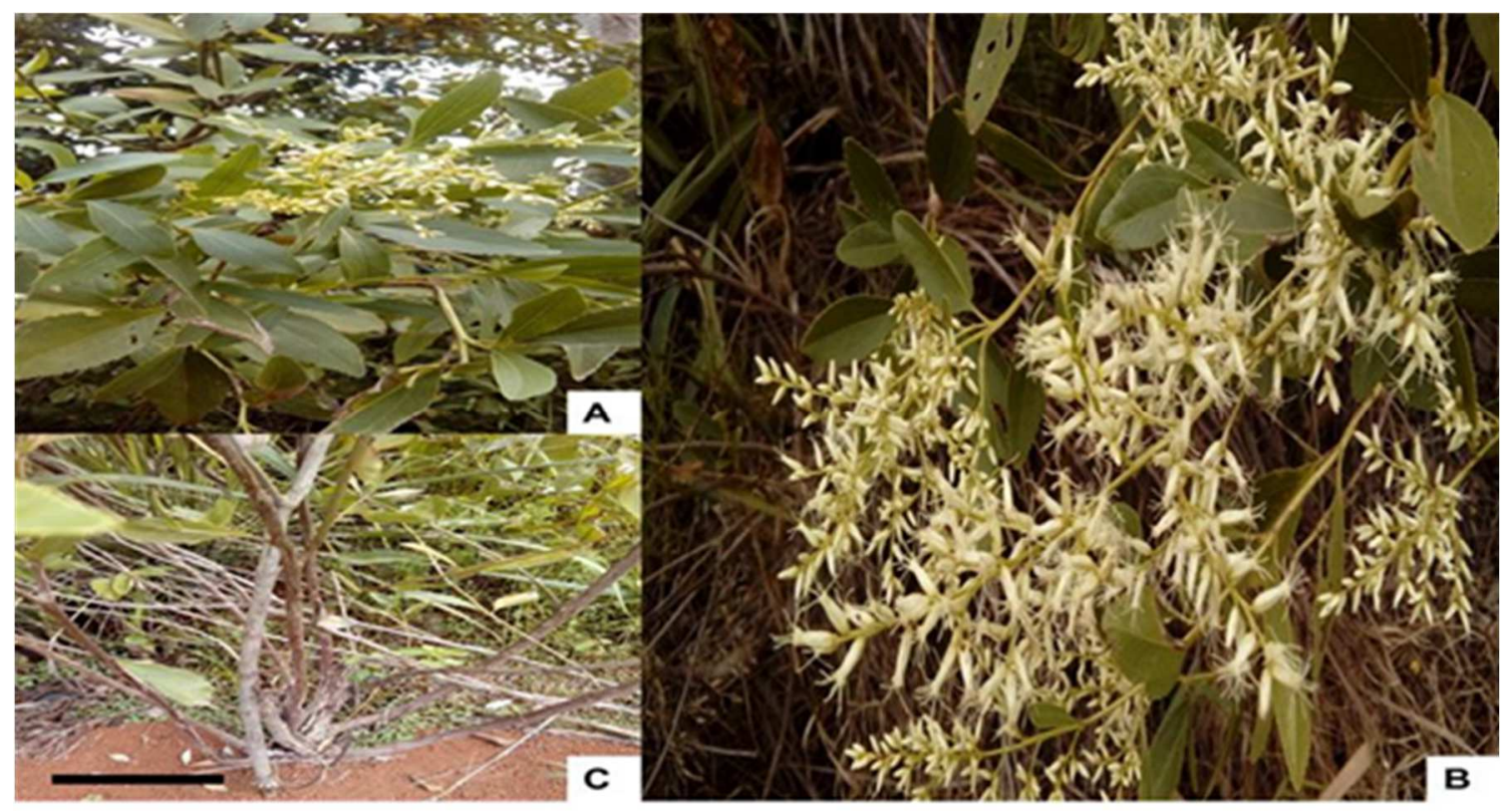

Figura 1. Indivíduo de $R$. crenulata. Em (A) parte aérea apresentando as folhas e início do estágio de inflorescência (flores fechadas), em (B) folhas e inflorescências em estágio avançado (flores abertas) e em (C) galhos. Barra: $90 \mathrm{~cm}$ de altura. 
Tabela 1. Perfil químico do óleo essencial dos galhos (OEG), folhas (OEF) e flores (OEFI) de R. crenulata por CG - EM. * (\%) Área de Retenção do pico para cada composto. O índice de retenção foi calculado conforme a literatura de Adams (2007) e Nist 11.

\begin{tabular}{|c|c|c|c|}
\hline \multirow[t]{2}{*}{ Composto } & OEG & OEF & OEFI \\
\hline & \multicolumn{3}{|c|}{ Área de Retenção (\%) } \\
\hline a-pineno & 1,09 & 0,47 & 0,33 \\
\hline Orcinil di-tiglato & 0,23 & 0,31 & - \\
\hline ס-3-careno & 0,11 & 0,42 & 9,76 \\
\hline$\beta$-ocimeno & 0,35 & - & 1,00 \\
\hline Trans- $\beta$-ocimeno & 0,39 & 0,33 & - \\
\hline y-terpineno & 3,07 & 0,78 & 0,74 \\
\hline$\beta$-felandreno & 1,01 & 0,16 & 1,27 \\
\hline$\beta$-mirceno & 0,26 & 0,32 & - \\
\hline$(E)$ - $\beta$-farneseno & 0,62 & 0,67 & - \\
\hline O-cimeno & 10,10 & 7,49 & - \\
\hline$p$-cimeno & 0,22 & 4,80 & - \\
\hline D-limoneno & 2,37 & 4,61 & 13,55 \\
\hline y-terpineno & 6,01 & 0,16 & - \\
\hline Óxido de cariofileno & 0,73 & - & - \\
\hline$\beta$-longipineno & 0,22 & 3,54 & 0,90 \\
\hline Aromadendreno & 0,39 & 0,30 & - \\
\hline Óxido de Aloaromadendreno & - & - & 4,26 \\
\hline Iso-cariofileno & 8,84 & - & 5,12 \\
\hline Germacreno D & 15,92 & 1,28 & 11,25 \\
\hline Y-muuroleno & - & 1,74 & 0,68 \\
\hline Cis-muurola-4(14),5-dieno & 0,62 & - & 2,44 \\
\hline$\alpha$-cubebeno & 9,17 & 23,49 & - \\
\hline Junenol & 3,41 & 5,08 & 4,72 \\
\hline 6-epi-shibunol & 3,36 & 0,55 & 0,23 \\
\hline a-eudesmol & 6,47 & 2,73 & 0,97 \\
\hline Criptomeridiol & - & 4,55 & 1,01 \\
\hline Canfeno & 0,12 & - & 7,34 \\
\hline$\beta$-bourboneno & 1,11 & 0,42 & 0,98 \\
\hline$\beta$-ilangeno & 9,21 & - & 2,18 \\
\hline$\beta$-elemeno & 4,72 & 6,08 & 0,37 \\
\hline Y-elemeno & - & 8,86 & 3,48 \\
\hline a-santalol & 2,08 & 1,23 & 0,22 \\
\hline Iso-longifolol & 0,33 & 5,11 & 0,45 \\
\hline Humulano-1,6-dien-3-ol & 1,00 & 3,74 & 23,75 \\
\hline Globulol & 0,13 & - & 0,82 \\
\hline 1-epi-cubenol & - & - & 0,67 \\
\hline Ledol & 2,07 & 0,65 & 0,43 \\
\hline Selin-6-en-4- $\alpha$-ol & 0,18 & - & 0,15 \\
\hline Biciclogermacreno & - & 3,79 & - \\
\hline Total Identificado (\%) & 95,91 & 93,66 & 99,07 \\
\hline
\end{tabular}

$\mathrm{Na}$ Figura 3 podem ser observados os resultados de porcentagem de inibição de crescimento dos óleos essenciais dos galhos, folhas e flores de $R$. crenulata frente à $C$. gloeosporioides in vitro nas concentrações $\left(100 ; 50 ; 25 ; 12,5 ; 6,25 ; 3,13\right.$ e $\left.1,56 \mu \mathrm{L} \mathrm{mL}^{-1}\right)$.

Podem-se observar na Figura 3, resultados eficientes na inibição de crescimento para C. gloeosporioides pelo óleo essencial das folhas, que apresentou ser mais eficaz inibindo o crescimento de C. gloeosporioides quando comparado ao óleo dos galhos e das flores que apresentaram menor efeito fungistático, respectivamente. Novamente se observa, que as maiores concentrações usuais apresentaram os melhores resultados de PIC. Importante detalhe para se comentar, é que os óleos essenciais de diferentes órgãos vegetais apresentam diferentes resultados. O óleo essencial das flores, foi o que menos teve uma efetiva ação antifúngica, como pode ser observado ainda na Figura (3), onde apresentou uma discreta inibição no crescimento apenas nas duas maiores concentrações, entretanto, em ambas as concentrações usuais, não houve diferença significativa conforme teste de Tukey.

Tabela 2. Atividade antioxidante dos óleos essenciais dos galhos (OEG), folhas (OEF) e flores (OEFI) de $R$. crenulata na redução do radical livre $D P P H$ em diferentes concentrações (50; 40; 30; 20; 10; $5 ; 2,5 ; 1,25$ e 0,625 $\mu \mathrm{L}$ $\left.\mathrm{mL}^{-1}\right)$. Médias seguidas de ( \pm ) desvio padrão. Letras diferentes (Minúscula) na mesma coluna apresentam

\begin{tabular}{lccc}
\hline Conc. $\mu \mathrm{L} \mathrm{mL}^{-1}$ & \multicolumn{4}{c}{ Atividade Antioxidante (\%) } \\
\hline & OEG & OEF & OEFI \\
50 & $100 \pm 0,00 \mathrm{aA}$ & $86,09 \pm 0,07 \mathrm{aB}$ & $20,55 \pm 0,06 \mathrm{aC}$ \\
40 & $100 \pm 0,00 \mathrm{aA}$ & $71,28 \pm 0,04 \mathrm{bB}$ & $15,12 \pm 0,13 \mathrm{bC}$ \\
30 & $48,74 \pm 0,10 \mathrm{bA}$ & $26,15 \pm 0,07 \mathrm{cB}$ & - \\
20 & $43,72 \pm 0,09 \mathrm{bA}$ & $17,21 \pm 0,02 \mathrm{~dB}$ & - \\
10 & $25,09 \pm 0,06 \mathrm{cA}$ & - & - \\
5 & - & - & - \\
2,5 & - & - & - \\
1,25 & - & - & - \\
0,625 & - & & - \\
\hline
\end{tabular}

Já na Figura 4 estão apresentados os resultados da porcentagem de inibição de crescimento dos óleos essenciais dos galhos, folhas e flores de $R$. crenulata frente à $C$. acutatum in vitro nas concentrações (100; 50; $25 ; 12,5 ; 6,25 ; 3,13$ e $1,56 \mu \mathrm{L} \mathrm{mL}^{-1}$ ).

As melhores eficiências de inibição para $C$. acutatum foram para os óleos dos galhos e folhas também nas maiores concentrações. O óleo essencial das flores apresentou a menor inibição de crescimento com máxima e única ação fungistática na maior concentração, demonstrando baixa proteção contra o desenvolvimento do fungo. Os resultados de menor porcentagem de inibição do crescimento micelial, foram observados para C. acutatum como pode ser observado na Figura (4), entretanto, merecida atenção deve ser tomada para ambos os óleos essenciais dos galhos e folhas que apresentam boa PIC para $C$. acutatum.

O experimento antifúngico para $S$. sclerotiorum, $C$. gloeosporioides e $C$. acutatum foram avaliados e comparados com o controle positivo, fungicida comercial Frowncide $^{\circledR} 500$ SC na concentração usual prédeterminada de $10 \mu \mathrm{L} \mathrm{mL}^{-1}$ com inibição máxima para as três cepas fúngicas testadas. O estudo das médias encontradas pelo teste de Scott-Knott revelou que, todas 
as concentrações diferiram estatisticamente do controle positivo, entretanto, com resultados inferiores ao obtido pelo fungicida de referência.

Deve-se destacar que, a comparação da diferença estatística pelo teste de Tukey, foi realizada entre as diferentes concentrações dos óleos essenciais para cada órgão vegetal avaliado, com respectiva taxa de inibição para determinação da melhor concentração usual. Já para o controle negativo (testemunha e DMSO), não houve inibição de crescimento dos fungos.

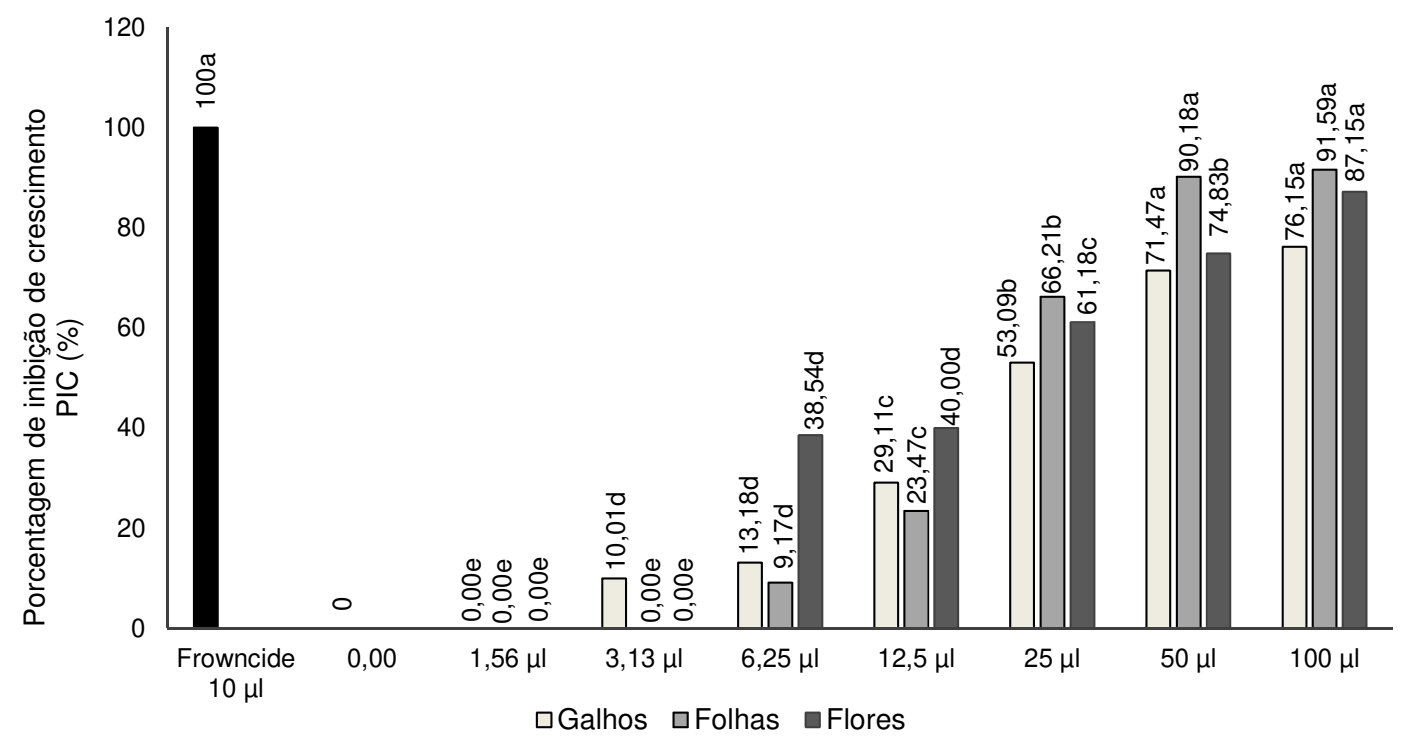

Figura 2. Porcentagem de Inibição de Crescimento (PIC) pelos óleos essenciais dos galhos, folhas e flores de $R$. crenulata frente à S. sclerotiorum. Letas iguais não diferem estatisticamente pelo teste de Tukey ( $p \leq 0,05 \%)$.

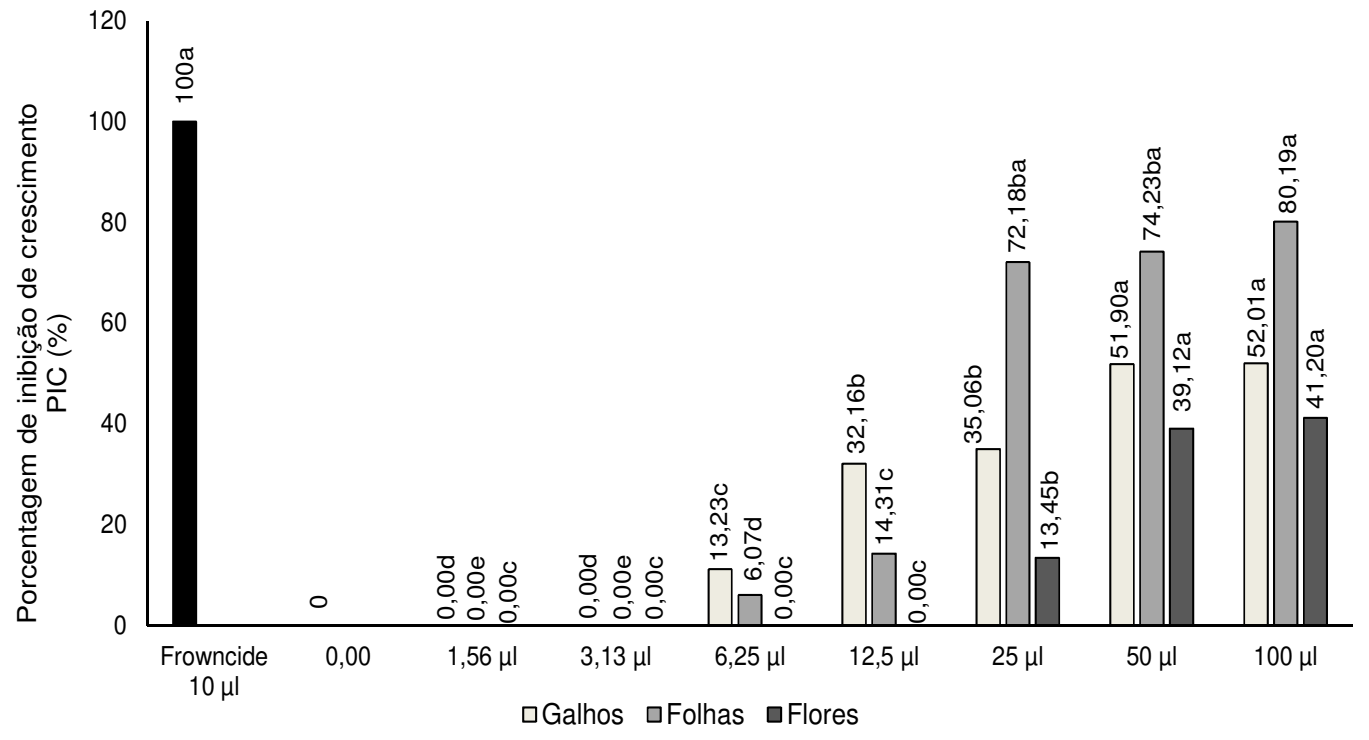

Figura 3. Porcentagem de Inibição de Crescimento (PIC) pelos óleos essenciais dos galhos, folhas e flores de $R$. crenulata frente à C. gloeosporioides. Letas iguais não diferem estatisticamente pelo teste de Tukey $(p \leq 0,05 \%)$. 


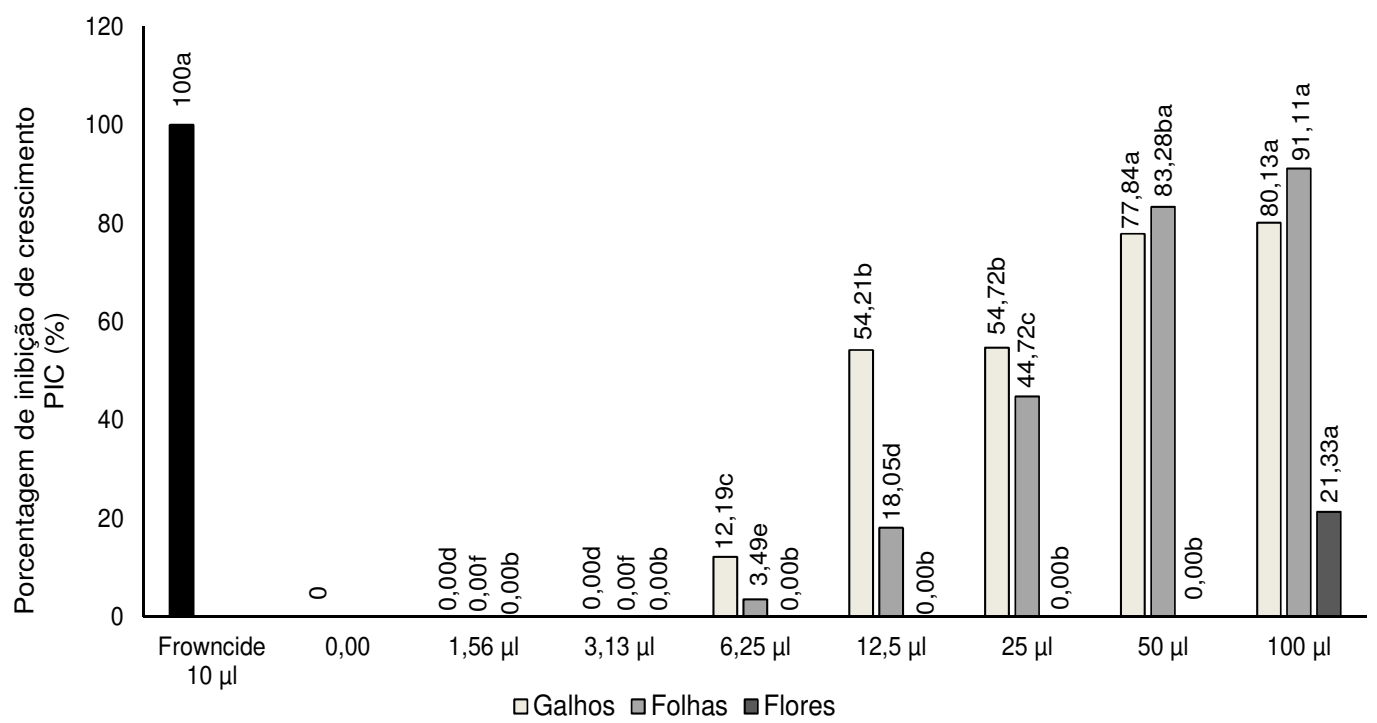

Figura 4. Porcentagem de Inibição de Crescimento (PIC) pelos óleos essenciais dos galhos, folhas e flores de R. crenulata frente à $C$. acutatum. Letas iguais não diferem estatisticamente pelo teste de Tukey $(p \leq 0,05 \%)$.

\section{DISCUSSÃO}

A espécie $R$. crenulata foi observada habitando áreas semi-alagadas próximas a rios e lagoas, os indivíduos avaliados neste estudo, apresentaram inflorescência no período entre outubro a dezembro para o estado de Goiás na região Sudoeste (Figura 1). As flores apresentam leve aroma adocicado, persistindo por longo período mesmo sob armazenagem em geladeira a $4^{\circ} \mathrm{C}$.

Estudo realizado por Pereira et al. (2019) encontraram indivíduos de $R$. crenulata habitando áreas de campo de murundus no sudoeste de Goiás, Brasil.

O mesmo foi observado por Scremin-Dias et al. (2018) onde estudaram a flora de campos úmidos calcários na serra da Bodoquena no estado do Mato Grosso do Sul, Brasil, onde descreveram a presença de $R$. crenulata com forma de vida anfíbia. Gasper et al. (2013) encontraram indivíduos de $R$. crenulata em área de componente florístico em floresta estacional decidual no estado de Santa Catarina, Brasil. Já Souza et al. (2007) avaliando a mesma espécie de $R$. crenulata descreveram em estudo, plantas com inflorescências no mês de abril, para o estado do Rio Grande do Sul, Brasil. Este estudo corrobora e acrescenta novos dados na literatura sobre os variados ambientes em que esta espécie de Asteraceae habita em diferentes tipos de regiões.

Os órgãos vegetativos aéreos de $R$. crenulata demonstraram ser ricos em óleo essencial, bem como em composição química. Foi observado como composto minoritário o orcinil di-tiglato, para o óleo do galho e folha. Mesmo ainda em baixa concentração em relação à área do pico no cromatograma pela análise em CG-EM, esse composto apresenta grande importância para a pesquisa. De acordo com Adams \& Dev (2009) os compostos tiglatos e angelatos contribuem significativamente na composição química do óleo essencial.

Inúmeras espécies de Asteraceae apresentam riqueza na constituição química de seus óleos essenciais, como pode ser observado nos trabalhos de Babady-Bila et al. (2017) com um total de 42 compostos identificados no óleo essencial de Eupatorium africanum, sendo os majoritários a-humuleno 8,90\%, edicariol 8,90\%, 10-EpiY-eudesmol 11,30\%, e $\beta$-eudesmol 49,1\%. Pandey et al. (2014), avaliaram o óleo essencial dos galhos em outra espécie do gênero Eupatorium, Eupatorium adenophorum onde encontraram cerca de 35 compostos, sendo os majoritários canfeno 12,05\%, a-felandreno 8,57\%, pcimeno $11,6 \%$, acetato de bornil $10,60 \%$ e acoradieno $10,11 \%$.

Padalia et al. (2009) encontraram um total de 49 compostos para o óleo essencial de E. adenophorum, sendo os majoritários canfeno 8,9\%, a-felandreno $9,6 \%$, p-cimeno $16,6 \%$, bornil acetato 15,$6 ; 15,9 ; 14,4 ; 9,4$ e 10,8\%, amorfo-4-em-7-ol 9,6; 14,8; 13,8; 17,7; 9,4 3 $9,9 \%$, e 3-acetoxiamorfa-4,7(11)-dien-8-ona com 8,3; 15,$2 ; 16,3 ; 15,9$ e $9,4 \%$. No estudo de Souza et al. (2007), os pesquisadores encontraram 34 compostos, sendo 8 traços para o óleo essencial das folhas de Eupatorium polystachyum, os majoritários foram $\beta$-pineno $14,7 \%$, $\beta$-mirceno $15,3 \%$, limoneno $22,8 \%$, $\beta$-cariofileno $10,4 \%$ e biciclogermacreno $12,0 \%$, e para o óleo essencial das inflorescências, 28 compostos sendo os majoritários $\beta$-pineno com 9,8\%, $\beta$-mirceno 10,8\%, limoneno $20,5 \%, \beta$-cariofileno $15,4 \%$, germacreno $D$ $9,45 \%$ e biciclogermacreno $19,2 \%$.

Bamba et al. (1993) encontraram para o óleo essencial de Eupatorium odoratum 38 compostos, sendo dois não 
identificados. Os majoritários $\alpha$-pineno 18,8\%, $\beta$-pineno $10,5 \%$, germacreno D $8,2 \%$, e pregeijereno $14,3 \%$. Podese inferir que a sazonalidade, área de coleta, tipo de solo, intensidade dos raios solares e altura em relação ao mar, bem como fatores genéticos influenciam consideravelmente na composição, bem como nos teores quantitativos (Ribeiro et al., 2018; Souza et al., 2012; De Morais, 2009). Observa-se uma grande variedade de compostos e teores relativos para inúmeras espécies de Eupatorium, entretanto, novas avaliações devem ser realizadas em outros grupos de indivíduos da mesma espécie em outros ambientes dentro do estado de Goiás para se ter uma possível variabilidade no perfil químico para $R$. crenulata, podendo assim, avaliar características únicas dessa espécie nas mais variadas fitofisionomias do Cerrado brasileiro.

Inúmeras espécies de Asteraceae são utilizadas na medicina tradicional, na fitoterapia, bem como na fitopatologia nos continentes Africano, Asiático, na Oceania e nas Américas para o tratamento e cura de várias doenças em humanos, animais e plantas agricultáveis (De Souza et al., 2017). Os teores dos diversos compostos em sinergismo ou em compostos puros do metabolismo secundário dos vegetais apresentam importante atividade antioxidante na redução de radicais livres como o oxigênio singleto. Os radicais livres são os responsáveis por inúmeros problemas genéticos, desencadeando patologias nos seres humanos e animais, bem como fitopatológicos nos vegetais.

Os antioxidantes apresentam importante ação de redução (sequestro) de inúmeras formas radicalares que estão envolvidas em inúmeros processos no desenvolvimento de tumores cancerígenos e na desestruturação de biomoléculas. De acordo com Jena et al. (2017) e Elseweidy et al. (2015), o estresse oxidativo está associado à produção dos grupos de radicais livres que apresentam alto potencial patogênico em biomoléculas, no DNA, no desenvolvimento de doenças como Alzheimer, aterosclerose, Parkinson, no envelhecimento precose, no diabetes, na artrite reumatóide e em doenças imunológicas, como lúpus eritematoso sistêmico.

Como agente antioxidante, os óleos essenciais são utilizados não somente no estudo de citotoxicidade ou na inibição dos efeitos deletérios de células cancerígenas, podendo também ser empregados no uso alimentício evitando a proliferação de microrganismos e na ação de inibição dos radicais livres (Scur et al., 2016).

Estudos avaliando a capacidade de redução de radicais livres com óleos essenciais vêm demonstrando importantes resultados, como nos estudos de Baczek et al. (2017), onde os pesquisadores obtiveram alta eficiência na porcentagem de redução do radical livre DPPH e FRAP com resultados de $86,80 \%$ e $88,18 \%$, e de 739,8 e $1178,0 \mathrm{Fe}^{2+} \mu \mathrm{mol} \mathrm{g}{ }^{-1}$ para os óleos essenciais de Tanacetum balsamita e Tanacetum vulgare, respectivamente. Scur et al. (2016) encontraram atividade antioxidante entre 16,19 a 4,01\%, com $\mathrm{IC}_{50}$ de 183,99 a $171,14 \mu \mathrm{L} \mathrm{mL} \mathrm{mL}^{-1}$ para o óleo essencial de Psidium cattleianum. Pandey et al. (2014) encontraram para o óleo essencial dos galhos de $E$. adenophorum atividade antioxidante entre 42,0 a $85,5 \%$ na redução do radical DPPH. Souza et al. (2007) avaliaram a atividade antioxidante pelo sequestro do radical livre DPPH a partir dos óleos essenciais das folhas e inflorescências de $E$. polystachyum ( $R$. crenulata) coletadas no estado do Rio Grande do Sul, Brasil, com efetiva redução radicalar na diluição 1:10 (v/v). Os resultados de porcentagem de redução neste estudo estão próximos aos obtidos entre os trabalhos na literatura avaliada.

Os óleos também vêm demonstrando em inúmeros trabalhos, efetiva ação antifúngica tanto para fungos patológicos (humanos e animais), como fitopatológicos nos mais variados tipos de vegetais que atualmente fazem parte do grupo dos vegetais economicamente importantes para a produção alimentícia. Todos os anos, os produtores de sementes (milho, soja, grão-de-bico) e de frutas (mamão, morango, abacate), e em algumas formas de legumes, apresentam perdas de produção, afetando a economia mundial. Dentre os inúmeros gêneros fúngicos causadores de fitopatológicas as espécies de $S$. sclerotiorum, $C$. gloeosporioides e $C$. acutatum apresentam sérias perdas na agroindústria.

A ação de inibição fúngica frente a $S$. sclerotiorum, $C$. gloeosporioides e C. acutatum apresentaram alta eficiência para às diferentes concentrações de óleo essencial de $R$. crenulata (Figuras 2, 3 e 4). Os melhores resultados de inibição foram observados para $S$. sclerotiorum, seguidos de $C$. gloeosporioides e $C$. acutatum. Entretanto, o óleo essencial das flores apresentou discreta inibição apenas na maior concentração (óleo puro) para $C$. acutatum não sendo a melhor opção para futuros testes em casas-de-vegetação e em campo.

Possivelmente as altas taxas de inibição para $S$. sclerotiorum, podem estar influenciadas pelo desenvolvimento biológico rápido que o fungo apresenta, e das condições de crescimento, onde devido à baixa temperatura de $20{ }^{\circ} \mathrm{C}$ os compostos de monoterpenos e diterpenos por sinergismo agem por maior tempo, devido à baixa taxa de volatilização destes compostos, que apresentam menor cadeia carbônica. Para corroborar esta discussão, alguns trabalhos apresentados, avaliaram essa volatilização em diferentes variáveis.

São inúmeros trabalhos que avaliam a cinética de volatilização versus tempo versus temperatura na constituição química de óleos voláteis. De acordo com Radünz et al. (2006), e Rocha et al. (2000), o tempo e temperatura influenciam na composição química, isso é óbvio, visto que, os fungos neste estudo não apresentam tempo de crescimento igual, o $S$. sclerotiorum tem seu pleno desenvolvimento em até 5 dias, já para $C$. gloeosporioides e $C$. acutatum uma previsão entre 12 a 16 dias na temperatura usual. Outras possibilidades podem estar na concentração de cada composto que apresenta atividade antifúngica, na ação pelo sinergismo do óleo essencial e a própria genética do fungo.

Outros estudos aplicando óleos essenciais apresentaram importantes resultados de inibição, como observados nos estudos de Silva et al. (2018), onde os pesquisadores avaliaram o óleo essencial das folhas de Psidium guajava coletados em duas épocas do ano frente à $S$. sclerotiorum. Neste estudo foi possível inibir entre 93,4 a $94,9 \%$ em uma concentração de $300 \mu \mathrm{L} \mathrm{mL}^{-1}$, e de 90,0 a $90,8 \%$ para a concentração intermediária de $200 \mu \mathrm{L} \mathrm{mL}^{-1}$, e na menor concentração de $100 \mu \mathrm{L} \mathrm{mL}^{-1}$ entre 77,5 a $80,0 \%$. 
Para Valadares et al. (2018), importantes resultados foram obtidos para inibição de $S$. sclerotiorum usando óleo essencial de Piper aduncum. No estudo supracitado, o óleo essencial das inflorescências apresentaram inibição de $100 \%$ para as concentrações 30, 40 e $50 \mu \mathrm{L}$ $\mathrm{mL}^{-1}$, e nas concentrações de 10 e $20 \mu \mathrm{L} \mathrm{mL}^{-1}$ com taxas de PIC de 85,85 e 99,83\%, sendo esta última, onde não houve diferença significativa para as demais concentrações superiores. Já para o óleo essencial das folhas de $P$. aduncum, o estudo relata taxas de inibição superiores a $96,31 \%$ para as concentrações de 10, 20, 30,40 e $50 \mu \mathrm{L} \mathrm{mL}^{-1}$. No estudo proposto por Ma et al. (2016), diferentes concentrações testadas entre 1,00 a $0,15 \mu \mathrm{L} \mathrm{mL}^{-1}$ do óleo essencial de Ziziphora clinopodioides na fase de vapor in vitro, os pesquisadores conseguiram inibir a germinação de escleródios de $S$. sclerotiorum em 75\%. Já Bajpai et al. (2008) encontraram resultado de $39,6 \%$ de inibição para $S$. sclerotiorum utilizando o óleo essencial de Silene armeria na concentração de $5 \mu \mathrm{L} \mathrm{mL}^{-1}$ correspondendo a 1000 ppm. Formas de antracnose causam sérios prejuízos em plantações de frutíferas anualmente, devido à podridão dos frutos ainda em desenvolvimento, na colheita, no transporte, no armazenamento, bem como no meio domiciliar. São inúmeras as espécies do gênero Colletotrichum que causam severas perdas na economia agrícola principalmente de países de clima tropical, onde há severa ação desses fungos. Xu et al. (2017) encontraram efeito fungicida para $C$. gloeosporioides utilizando 1-Metilciclopropeno (1-MCP). O 1-MCP suprimiu o desenvolvimento da antracnose nos frutos de manga inoculadas com $C$. gloeosporioides. Os frutos controle com 6 dias já haviam total deterioração, enquanto os frutos tratados com 1-MCP apresentaram apenas incidência de 45,7\%. A lesão ocasionada pelo fungo também apresentou diâmetro médio inferior de 5,67 a $15 \mathrm{~mm}$, contra o diâmetro da lesão dos frutos controle de 28,33 a $66 \mathrm{~mm}$, indicando assim, significativa supressão da antracnose causada pelo $C$. gloeosporioides em frutos de manga.

Diversos trabalhos vêm demonstrando efetiva ação fungistática por óleos essenciais, como nos estudos de Júnior et al. (2009) onde avaliaram o efeito fungitóxico de óleos essenciais de Lippia sidoides, Ocimum gratissimum, Cymbopogon citratus, Lippia citriodora e Psidium guayava contra $C$. gloeosporioides onde obtiveram porcentagens de inibição de 100 a 44\% para concentrações de 1 a $10 \mu \mathrm{L} \mathrm{m}^{-1}$. Bajpai et al. (2008) testaram o óleo essencial de $S$. armeria em uma concentração de $5 \mu \mathrm{L}$ (1000 ppm disco) para Fusarium oxysporum, Fusarium solani, Phytophthora capsici, Colletotrichum capsici, Botrytis cinerea e Rhizoctonia solani, com taxa de inibição de 54,0; 67,6; 59,6; 60,3; 65,6 e $58,0 \%$, respectivamente. E Pereira et al. (2007) encontraram inibição de $100 \%$ frente a Colletotrichum musae e C. gloeosporioides causadores da podridão da banana com óleos essenciais de $C$. citratus e Eucalyptus citriodora em diferentes concentrações.

Outra forma infectante de frutas, hortaliças e legumes, o fungo $C$. acutatum apresenta severa ação de deterioração de vegetais no desenvolvimento pleno. Oliveira et al. (2019) encontraram taxas de inibição entre 46,26 a 92,99\% em concentrações que variaram entre 31 a $500 \mu \mathrm{L} \mathrm{L}^{-1}$ de óleo essencial de $L$. sidoides para $C$. acutatum. Pineda et al. (2018) observaram importante atividade de inibição para $C$. acutatum em diferentes extratos e óleo essencial de Petroselinum crispum. De Oliveria et al. (2016) avaliaram uma outra espécie de Colletotrichum, o $C$. musae que ataca plantações de diferentes espécies de bananas. No estudo, os pesquisadores avaliaram a PIC para o óleo essencial do alecrim pimenta, cravo-da-índia e eucalipto, onde obtiveram resultados entre 95,8 a $100 \%$ para concentrações de 25,50 e $100 \mu \mathrm{L} \mathrm{L}^{-1}$, e como controle o carbendazim. O óleo essencial na concentração de 400 $\mu \mathrm{g} \mathrm{m}^{-1}$ inibiu completamente o desenvolvimento de $C$. acutatum nas primeiras 72 horas, e após este período, a percentagem de inibição caiu para 78\% em 264 horas. Já Dias-Arieira et al. (2010) avaliaram a inibição micelial para $C$. acutatum em diferentes concentrações de óleo essencial de Azadirachta indica e E. citriodora, onde também encontraram boa eficiência com taxas de inibição entre 84,4 a $74,4 \%$, e de 91,1 a $35,6 \%$, respectivamente.

O estudo de novos fungicidas com características naturais obtidos a partir do metabolismo secundário dos vegetais, como os óleos essenciais, apresenta em inúmeros estudos efetiva atividade antifúngica, baixo efeito tóxico para humanos, solo, água, nos animais e demais formas de vida, principalmente nos insetos polinizadores (Durço et al., 2020; Jassbi et al., 2018; Bayala et al., 2018; Oliveira et al., 2016; Coitinho et al., 2011).

Outro ponto importante não somente para o meio ambiente, é o valor do estudo para o desenvolvimento de um novo fungicida natural, que apresenta maior economia quando comparados aos observados no desenvolvimento de uma molécula sintética, visto que, o mercado de óleos essenciais vem crescendo a cada ano e em resposta a eventuais ações contra resistência aos fungicidas comerciais (Speziali, 2012; Bizzo et al., 2009; De Castro et al., 2005). Estudos vêm sendo elaborados como forma de avaliação de inúmeras espécies fúngicas que estão apresentando resistência aos fungicidas comerciais de maior empregabilidade, devido ao uso contínuo, muitas das vezes em várias aplicações ao ano. Por exemplo, cepas de $C$. gloeosporioides e $C$. acutatum já demonstram serem resistentes ao fungicida sintético Carbendazim conforme estudo de Zhang e Huang (2007).

\section{CONCLUSÕES}

Os óleos essenciais de $R$. crenulata apresentaram quantitativos de rendimento satisfatórios para os galhos, folhas e flores. Vários compostos majoritários foram observados para as amostras. Os óleos apresentaram alta, média e baixa eficiência na redução do radical livre DPPH respectivamente. Quanto à atividade antifúngica os óleos apresentaram satisfatória inibição de crescimento para as cepas avaliadas de $S$. sclerotiorum e C. gloeosporioides, o mesmo não foi observado para $C$. acutatum nos ensaios in vitro. Novos estudos deverão ser realizados avaliando a capacidade fungicida destes óleos em casas-de-vegetação e ou em campo para que se possa verificar a cinética de inibição micelial em ambiente controlado e não controlado, outro possível uso na biotecnologia, seria a produção por encapsulamento do óleo essencial havendo estudos sobre a sua ação por tempo prolongado no ambiente agrícola. 


\section{AGRADECIMENTOS}

Ao Instituto Federal Goiano, Campus Rio Verde; a Universidade Federal de Jataí; a Universidade Federal de Goiás; Universidade Federal de São Carlos; aos Laboratórios de Bioensaios e Biomoléculas, Química Tecnológica, Produtos Naturais; a Central Analítica Multiusuário - CEMA; ao Herbário Jataiense; aos órgãos de fomento em pesquisa, CAPES, FINEP, CNPq e FAPEG, esta última pela bolsa de mestrado em Agroquímica para o primeiro.

\section{REFERÊNCIAS BIBLIOGRÁFICAS}

Adams, R.P. 2007. Identification of essential oil components by gas chromatography/mass spectrometry. 4th Edition. Allured Publishing Corporation 362 South Schmale Road, Illinois, 698 pp.

Adams, R.P. \& V. Dev. 2009. Synthesis and GC-MS analysis of angelates and tiglates as na aid to identification of these components in essential oils. Flavour and Fragrance Journal 25: 71-74.

Allahverdiyev, A., N. Duran, M. Ozguven \& S. Koltas. 2004. Antiviral activity of the volatile oils of Melissa officinalis L. against Herpes simplex vírus type-2. Phytomedicine 11: 657-661.

Amaike, S. \& N. P. Keller. 2011. Aspergillus flavus. Annual Review of Phytopathology 49: 107-133.

Babady-Bil, P., D. T. Dinangayi, D. S-T. Tshibangu, E. Lengbiye, J-P. Ngbolua \& P. M. Tshimankinda. 2017. Chemical composition and in vitro antibacterial activity of essential oil from Eupatorium africanum Oliv. \& Hiern. American Journal of Essential Oils and Natural Products 5: 01-06.

Baczek, K. B., O. Kosakowska, J. L. Przybył, E. PióroJabrucka, R. Costa, L. Mondello, M. Gniewosz, A. Synowiec \& Z. Weglarz. 2017. Antibacterial and antioxidant activity of essential oils and extracts from costmary (Tanacetum balsamita L.) and tansy (Tanacetum vulgare L.). Industrial Crops and Products 102: 154-163.

Bagherabadi, S., D. Zafari \& G. ANVAR. 2018. Colletotrichum gloeosporioides s. str., the causal agent of a leaf spot disease of Schefflera arboricola in Iran. Mycologia Iranica 5: 29-34.

Bajpai, V. K., S. Shukla \& S. C. Kang. 2008. Chemical composition and antifungal activity of essential oil and various extract of Silene armeria L. Bioresource Technology 99: 8903-8908.

Bamba, D., J-M. Bessière, C. Marion, Y. Pélissier \& I. Fourasté. 1993. Essential oil of Eupatorium odoratum. Planta Med 59: 184-185.

Bayala, B., I. H. N. Bassole, S. Maqdasy, S. Baron, J. Simpore \& J-M. A. Lobaccaro. 2018. Cymbopogon citratus and Cymbopogon giganteus essential oils have cytotoxic effects on tumor cell cultures. Identification of citral as a new putative anti-proliferative molecule. Biochimie 153: 162-170.

Bizzo, H. R., A. M. C. Hovell \& C. M. Rezende. 2009. Óleos essenciais no Brasil: aspectos gerais, desenvolvimento e perspectivas. Química Nova 32: 588594.
Bremer, K. 1994. Asteraceae - Cladistics \& Classification. Timber Press, Portland, 728 pp.

Carmona, M. \& F. Sautua. 2017. La problemática de la resistencia de hongos a fungicidas. Causas y efectos em cultivos extensivos. Agronomía \& Ambiente 37: 1-19.

Celoto, M. I. M., M. F. S. Papa. L. V. S. Sacramento \& F. J. Celoto. 2008. Atividade antifúngica de extratos de plantas a Colletotrichum gloeosporioides. Acta Scientiarum Agronomy 30: 1-5.

Coitinho, R. L. B. C., J. V. Oliveira, M. G. C. G. Júnior \& C. A. G. Câmara. 2011. Toxicidade por fumigação, contato e ingestão de óleos essenciais para Sitophilus zeamais Motschusky, 1885 (Coleoptera: Curculionidae). Ciência e Agrotecnologia 35: 172-178.

Cunico, M. M., G. M. Cirio, O. G. Miguel, M. D. Miguel, D. P. Montrucchio, C. G. Auer \& A. Grigoletti Júnior. 2002. Contribuição ao estudo da atividade antifúngica de Maytenus ilicifolia Mart. ex Reiss. Revista Brasileira de Farmacognosia 12: 69-73.

De Castro, C., M. L. Silva, A. L. Pinheiro \& L. A. G. Jacovine. 2005. Análise econômica do cultivo e extração do óleo essencial de Melaleuca alternifolia Cheel. Revista Árvore 29: 241-249.

De Morais, L. A. S. 2009. Influência dos fatores abióticos na composição química dos óleos essenciais. Horticultura Brasileira 27: S4050-S4063

De Oliveira, E. S., F. M. P. Viana \& M. V. V. Martins. 2016. Alternativas a fungicidas sintéticos no controle da antracnose da banana. Summa Phytopathologica 42: 340-350.

De Souza, T. J. T., S. A. L. Bordignon \& M. A. Apel. 2017. A chemometric approach to the investigation of the intraspecific variability of the volatile oil of Eupatorium tremulum from Southern Brazil. Journal of Natural Products 80: 45-52.

Dias-Arieira, C. R., L. R. Ferreira, J. O. Arieira, E. G. Miguel, M. A. Donega \& R. C. F. Ribeiro. 2010. Atividade do óleo de Eucalyptus citriodora e Azadirachta indica no controle de Colletotrichum acutatum em morangueiro. Summa Phytopathologica 36: 228-232.

Durço, B. B., E. R. T. Filho, P. T. S. Soares, M. L. Q. K. Ribas, M. C. K. H. Duarte \& E. A. Esmerino. 2020. Uso de óleos essenciais como alternativa conservante Clean Label em produtos lácteos. Alimentos: Ciência, Tecnologia e Meio Ambiente 1: 83-102.

Elseweidy, M. M., N. M. Younis, S. E. Elswefy, F. R. Abdallah, S. I. El-Dahmy, G. Elnagar \& H. M. Kassem. 2015. Atheroprotective potentials of curcuminoids against ginger extract in hypercholesterolaemic rabbits. Natural Product Research 29: 961-965.

Estrela, J. L. V., M. Fazolin, V. Catani, M. R. Alécio \& M. S. De Lima. 2006. Toxicidade de óleos essenciais de Piper aduncum e Piper hispidinervum em Sitophillus zeamais. Pesquisa Agropecuária Brasileira 41: 217-222. Freddo, Á. R., A. Lewandowski, C. Busso, F. E. Cechim, I. C. Zorzzi, M. S. Rey, N. L. Dalacosta \& S. M. Mazaro. 2016. Óleo essencial de Aloysia citriodora no controle de Sclerotinia sclerotiorum em pepino e atividade antifúngica in vitro. Cultura Agronômica 25: 373-386.

Garcia, R. A., F. C. Juliatti, K. A. G. Barbosa \& T. A. Cassemiro. 2012. Atividade antifúngica de óleo e extratos vegetais sobre Sclerotinia sclerotiorum. Bioscience Journal 28: 48-57. 
Gasper, A. L., A. Uhlmann, L. Sevegnani, D. V. Lingner, M. J. Rigon-Júnior, M. Verdi, A. StivalSantos, S. Drececk, M. Sobral \& A. C. Vibrans. 2013. Inventário florístico florestal de Santa Catarina: espécies da floresta estacional decidual. Rodriguésia 64: 427-443.

Gomes, P. R. B., J. B. Reis, J. C. Da Silva, R. W. S. De Oliveira, M. L. De Paula, H. C. Louzeiro, V. E. M. Filho \& M. A. Fontenele. 2019. Avaliação da toxicidade e atividade moluscicida do óleo essencial Cinnamomum zeylanicum Blume contra o caramujo Biomphalaria glabrata (Say, 1818). Revista Colombiana de Ciencias Químico-Farmacéuticas 48: 122-127.

Hattori, E.K.O. \& J. N. Nakajima. 2011. A família Asteraceae na Reserva Ecológica do Panga, Uberlândia, Minas Gerais, Brasil. Hoehnea 38: 165-214.

Heiden, G., R. L. Barbieri, R. A. Wasum, L. Scur \& M. Sartori. 2007. A família Asteraceae em São Mateus do Sul, Paraná. Revista brasileira de Biociências 5: 249-251. Jassbi, A. R., Y. Mirzaie, F. Omidreza \& A. Mojtaba. 2018. Composition and cytotoxic activity of the essential oils of Mentha mozaffarianii Jamzad at different phenological stages. Current Bioactive Compounds 14: 191-196.

Jena, S., A. Ray, A. Banerjee, A. Sahoo, N. Nasim, S. Sahoo, B. Kar, J. Patnaik, P. C. Panda \& S. Nayak. 2017. Chemical composition and antioxidant activity of essential oil from leaves and rhizome of Curcuma angustifolia Roxb. Natural Product Research 31: 21882191.

Júnior, I. T. S., N. L. P. Sales \& E. R. Martins. 2009. Efeito fungitóxico de óleos essenciais sobre Colletotrichum gloeosporioides, isolado do maracujazeiro amarelo. Biotemas 22: 77-83.

Ma, B-X., X-Q. Ban, J-S. He, B. Huang, H. Zeng, J. Tian, Y-X. Chen \& Y-W. Wang. 2016. Antifungal Activity of Ziziphora clinopodioides Lam. essential oil against Sclerotinia sclerotiorum on rapessed plant (Brassica campestris L.). Crop Protection 89: 289-295.

Maia, J. G. S., M. G. B. Zoghbi, E. H. A. Andrade, M. H. L. Da Silva, A. I. Luz \& J. D. Da Silva. 2002. Essential oils composition of Eupatorium species growing wild in the Amazon. Biochemical Systematics and Ecology 30: 1071-1077.

Maia, A. I. V., M. C. M. Torres, O. D. L. Pessoa, J. E. S. A. Menezes, S. M. O. Costa, V. L. R. Nogueira, V. M. M. Melo, E. B. Souza, M. G. B. Cavalcante \& M. R. J. R. Albuquerque. 2010. Óleos essenciais das folhas de Vernonia remotiflora e Vernonia brasiliana: composição química e atividade biológica. Química Nova 33: 584-586. Martinazzo, A. P., F. S. Oliveira \& C. E. S. Teodoro. 2019. Antifungal activity of Cymbopogon citratus essential oil against Aspergillus flavus. Ciência e Natura 41: 01-08. Maleski, L. T., M. T. De Souza, M. T. De Souza, L. K. Aguiar, B. C. Durau \& M. A. C. Zawadneak. 2019. Toxicidade do óleo essencial de Raulinoreitzia crenulata (Asteraceae) e seu constituinte majoritário contra Aphis forbesi (Hemiptera: Aphididae). Anais do Congresso Brasileiro de Fitossanidade, 5.

Menezes Filho, A. C. Pde., W. C. Souza \& C. F. S. Castro. 2020. Atividades antioxidante e antifúngica dos óleos essenciais de Cochlospermum regium frente à Sclerotinia sclerotiorum e Colletotrichum gloeosporioides. Colloquium Agrariae 16: 109-116.

Mezza, G. N., A. V. Borgarello, N. R. Grosso, H. Fernandez, M. C. Pramparo \& M. F. Gayol. 2018.
Antioxidant activity of rosemary essential oil fractions obtained by molecular distillation and their effect on oxidative stability of sunflower oil. Food Chemistry, 242: 9-15.

Oliveira, E. S., F. M. P. Viana \& M. V. V. Martins. 2016. Alternativas a fungicidas sintéticos no controle da antracnose da banana. Summa Phytopathologica 42: 340-350.

Oliveira, J., E. M. Gloria, M. C. M. Parisi, J. S. Gaggio, P. P. M. Silva, C. M. S. Ambrosio \& M. H. F. Spoto. 2019. Antifungal activity of essential oils associated with carboxymethylcellulose against Colletotrichum acutatum in strawberries. Scientia Horticulturae 243: 261-267.

Padalia, R. C., D. S. Bisht, S. C. Joshi \& C. S. Mathela. 2009. Chemical composition of the essential oil from Eupatorium adenophorum Spreng. Journal of Essential Oil Research 21: 522-524.

Pandey, A. K., M. Mohan, P. Singh, U. T. Palni \& N. M. Tripathi. 2014. Chemical composition, antibacterial and antioxidant activity of essential oil of Eupatorium adenophorum Spreng. from Eastern Uttar Pradesh, India. Food Bioscience 7: 80-87.

Pereira, A. J., L. G. Aguiar, D. G. Silva, M. Vivas \& S. F. Silveira. 2007. Inibição in vitro do crescimento micelial de Colletotrichum musae e Colletotrichum gloeosporioides por óleo essencial de Cymbopogom citratus (DC.) Stapf e Eucalyptus citriodora Hooker. XL Congresso Brasileiro de Fitopatologia. Brasil, 32: 185.

Pereira, F. C., L. F. De Souza, F. A. G. Guilherme, J. C. Freire \& A. M. Teles. 2019. Diversidade de Asteraceae em um campo de murundus no sudoeste de Goiás, Brasil. Rodriguesia 70: e00412017.

Pineda, R., S. Vizcaíno, C. M. García, J. H. Gil \& D. Durango. 2018. Antifungal activity of extracts, essential oil and constituents from Petroselinum crispum against Colletotrichum acutatum. Revista Facultad Nacional de Agronomía 71: 8563-8572.

Radünz, L. L., E. C. Melo, L. C. A. Barbosa, R. H. S. Santos, F. F. Barbosa \& A. P. Martinazzo. 2006. Influência da temperatura do ar de secagem no rendimento do óleo essencial de hortelã-comum (Mentha x villosa Huds). Engenharia na Agricultura 14: 250-257.

Ribeiro, S. M., O. H. Bonilla \& E. M. P. Lucena. 2018. Influência da sazonalidade e do ciclo circadiano no rendimento e composição química dos óleos essenciais de Croton spp. da Caatinga. Iheringia 73: 31-38.

Rocha, S. F. R., L. C. Ming \& M. O. M. Marques. 2000. Influência de cinco temperaturas de secagem no rendimento e composição do óleo essencial de citronela (Cymbopogon winterianus Jowitt). Revista Brasileira de Plantas Medicinais 3: 73-78.

Scremin-Dias, E., V. J. Pott, G. A. Damasceno-Júnior, A. C. M. Cristaldo, F. A. Dias \& A. Pott. 2018. Flora de campos úmidos calcários da Serra da Bodoquena. Iheringia 73: 80-92. Doi: http://doi.org/10.218262446$8231201873 s 80$

Scur, M. C., F. G. S. Pinto, J. A. Pandini, W. F. Costa, C. W. Leite \& L. G. Temponi. 2016. Antimicrobial and antioxidant activity of essential oil and different plant extracts of Psidium cattleianum Sabine. Brazilian Journal of Biology 76: 101-108.

Silva, E. A. J., V. P. Da Silva, C. C. F. Alves, J. M. Alves, E. L. Souchie \& L. C. A. Barbosa. 2018. Chemical composition of the essential oil of Psidium 
guajava leaves and its toxicity against Sclerotinia sclerotiorum. Semina: Ciências Agrárias 39: 865-874.

Sobrinho, A. C. N., S. M. De Morais, E. B. De Souza \& R. O. S. Fontenelle. 2017. The genus Eupatorium L. (Asteraceae): A review of their antimicrobial activity. Journal of Medicinal Plants Research 11: 43-57.

Souza, T. J. T., M. A. Apel, S. Bordignon, N. I. Matzenbacher, J. Â. S. Zuanazzi \& A. T. Henriques. 2007. Composição química e atividade antioxidante do óleo volátil de Eupatorium polystachyum DC. Brazilian Journal of Pharmacology 17: 368-372.

Souza, M. E., H. G. Lancelle, C. E. Tonn, M. Fe Andres \& A. Gonzalez-Coloma. 2012. Insecticidal and nematicidal essential oils from Argentinean Eupatorium and Baccharis spp. Biochemical Systematics and Ecology 43: $132-138$.

Speziali, M. G. 2012. De aromas e perfumes, mercado da indústria do "cheiro". Química Nova 35: 861-864.

Tariq, S., S. Wani, W. Rasool, K. Shafi, M .A. Bhat, A. Prabhakar, A. H. Shalla \& M. A. Rather. 2019. A comprehensive review of the antibacterial, antifungal and antiviral potential of essential oils and their chemical constituents against drug-resistant microbial pathogens. Microbial Pathogenesis 134: 103580.

Valadares, A. C. F., C. C. F. Alves, J. M. Alves, I. P. B. De Deus, J. G. Oliveira Filho, T. C. L. Dos Santos, H. J.
Dias, A. E. M. Crotti \& M. L. D. Miranda. 2018. Essential oils from Piper aduncum inflorescences and leaves: chemical composition and antifungal activity against Sclerotinia sclerotiorum. Anais da Academia Brasileira de Ciências 90: 2691-2699.

Valente, P. M., E. A. Lopes, M. C. Pereira, C. R. Oliveira \& V. M. M. Valente. 2018. Bioprospecção para atividade antifúngica do óleo essencial das folhas de Callistemon viminalis. Nucleus 15: 265-270.

Volpato, A., G. M. Galli, G. Campigotto, P. Glombowsky, C. V. Santos, A. S. S. Da Silva \& R. A. Vaucher. 2018. Avaliação in vitro dos efeitos inseticida e larvicida de oito óleos essenciais sobre o cascudinho aviário (Alphitobius diaperinus). Archives of Veterinary Science 23: 84-90.

Xu, X., H. Lei, X. Ma, T. Lai, H. Song, X. Shi \& J. Li. 2017. Antifungal activity of 1-methylcyclopropene (1MCP) against anthracnose (Colletotrichum gloeosporioides) in postharvest mango fruit and its possible mechanisms of action. International Journal of Food Microbiology 241: 1-6.

Zhang, R. L. \& J. S. Huang. 2007. Cloning of a carbendazim resistant gene from Colletotrichum gloeosporioides of mango in South China. African Journal of Biotechnology 6: 143-147. 